\title{
Microcornea-myopic chorioretinal atrophy-telecanthus syndrome
}

INSERM

\section{Source}

INSERM. (1999). Orphanet: an online rare disease and orphan drug data base.

Microcornea-myopic chorioretinal atrophy-telecanthus syndrome. ORPHA:369970

Microcornea-myopic chorioretinal atrophy-telecanthus syndrome is rare, genetic, developmental defect of the eye disease characterized by childhood onset of mild to severe myopia with microcornea and chorioretinal atrophy, typically associated with telecanthus and posteriorly rotated ears. Other variable features include early-onset cataracts, ectopia lentis, ecotpia pupilae and retinal detachment. 